\title{
The Evaluation of the Cultural Risk in the Small and Medium Albanian Enterprises: A Case Study - SMEs in the Gjirokastra Region
}

\author{
Msc. Lorenc Koçiu \\ "Eqrem Çabej" University, Gjirokastra \\ Email: kociulorenc@yahoo.com \\ Doc. Msc. Romeo Mano \\ "Eqrem Çabej” University, Gjirokastra \\ Email: manoromeo2002@yahoo.com \\ Msc. Armand Hysi \\ "Eqrem Çabej" University, Gjirokastra \\ Email: info@brilanthotel.com
}

Doi:10.5901/mjss.2015.v6n2p133

\begin{abstract}
The SMEs are the engine of the economic development of a country. This is true also in the case of the economic development of Albania. We should also show care when we talk about the identification, evaluation and the way they cope with different risks they encounter every day. In our article we will try to evaluate the cultural risk of the Albanian SMEs. For our article we polled several Gjirokastra-based SMEs. The data gathered were processsed through the SPSS Statistics version 21 using Logistic Regression, to determine the degree of influence of the factors of cultural risk. At the end of our article we come to the conclusion that although cultural risk is a new and little known notion to the Albanian SMEs, it certainly influences their activity. For this reason, SMEs should pay great attention to the cultural risk and its elements, so as to keep it under control since it cannot be eliminated.
\end{abstract}

Keywords: risk, cultural risk, SME, Gjirokastra, SPSS 21.

\section{Introduction}

SMEs have been designated as one of the greatest promoters of the economic development of a country. SMEs represent a form business organization where different problems appear. In the developing countries part of which Albania is, SMEs have an extremely great importance. In Albania their number is 101917, the total amount of the businesses is 102767, so they make up about $99 \%$ of the total number of businesses (INSTAT, 2013). So the Albanian SMEs occupy a considerable place in the Albanian economy. They are important not only from the point of view of their extent throughout the Republic of Albania, but also from the viewpoint of their percentage compared to the big businesses and to the other businesses which operate in the field of agriculture.

The definition of SME varies form country to contry. In Albania the definition of SME has been amended by Law Nr 8957, dated 17.10.2002 "On the small and medium entrerprises", changed. Are called Microenterprises those enterprises, which employ up to 9 employees and their annual turnover does not exceed 10 million lek ${ }^{1}$. Are called Small enterprises those enterprises which employ between 10 to 49 employees and have an annual balance sheet less than 50 million lek. Are called Medium enterprises those enterprises which employ between 50 to 249 employees, have an anual balance sheet up to 250 million lek.

The risk which SMEs deal with in their daily acitivity, for example, when they take decisions, or execute them in practice, or when they hire personnel, and also in many other issues is very different from the risk which big business deals with. In our article we will focus on the evaluation of the influence which the cultural risk has on the SME. The cultural risk is a new and almost unknown notion to the Albanian SMEs. The cultural risk of the organization has to do

${ }^{1}$ Lek - is called albanian money 
with the code of behaviour of the individuals and groups inside the organization which define the ability to identify and evaluate, to have open discussions and to act in the conditions of actual and perceived future risk (Levy, Lamarre, \& Twining, 2010). The cultural risk is a term, which describes the values, beliefs, knowledge, and the understanding of the risk by the workers of an organization, or by the groups inside the organization.

The cultural risk, as a concept, is closely related to the concept of the culture of the organization. The culture of the organization represents the way of behaving inside the organization, the style or its personality. Culture, by default, is represented as stable, which means that once it is etablished, cannot be changed easily (Manxhari, 2010).

According to Edgar Schein (2010) the culture of the organization is a pattern of suppositions formed, discovered or otherwise developed by a certain group, while it learns how to cope with the problems of adapting to the external environment and integrating into the inside environment, and which has functioned so good as to be deemed worthy of being transmitted to the new members as a right way to be perceived, and felt in relation to those problems.

\section{The Goals of the Article}

The main goal of this article is the evaluation of the cultural risk and of the factors which influence it. In order to achive the main goal other secondary goals were set, as follows;

a - The highlighting of the fact whether the level of reaction to mistakes the organization made in the past affects the cultural risk

b - The highlighting of the fact whether the level of observance of the work norms on the part of the workers affects the cultural risk

\section{Methodology}

In order to successfully carry out this study we have studied SMEs which are based in the Gjirokastra region and we have been able to secure trustworthy data from these subjects through the questionnaire they were asked to fill in. The questionnaire has been compiled in order to gather key data, necessary to evaluate the cultural risk. Also to successfully carry out this study it is necessary to secure the secondary data. These secondary data have been secured by utilizing the contemporary literature, which supports our study theoretically, the official data of the Albanian institutions, and other sources.

Also to evaluate the cultural risk we will use the logistic regression (Bierens, 2008). Logistic regression aims at finding the model in the shape of a more suitable linear mathematical equation which describes the relationship between the dependent variable and a set of independent case study variables (Mano, 2005).

The data are processed through the SPSS Statistics version 21, which processes through the logistic regression quality data of the nominal and ordinal type in its structure. The dependent variable is a nominal dichotomus data, which takes value only 1 or 0 . The independent variables are evaluated as ordinal data, which are measured with 5 Likert scale. This is the reason why is chosen this methodology, to process these data through SPSS version 21 with logistic regression.

The questionnaire has been compiled based on the diagram showing the cultural risk elements presented by Levy at al (2010), according to whom 10 elements have been identified, but for our purposes we have made use of only 7 elements. This is due to the fact that when workers from a country which is different from the country where the experiment was initially carried out are polled, cultural differences which have a great influence and could change the outcome, should be kept in mind.

These elements (independent variables) for Albanian SMEs are as follows:

1 - The Level of Communication of the workers regarding the risks which the organization faces (LOC)

2 - The Level of Tolerance to the workers of the mistakes they make (LOT)

3 - The Level of Opposition to new ideas (LOPNI)

4 - The Level of Reaction to mistakes the organization made in the past (LRMP)

5 - The Level of Reaction to external changes (LREC)

6 - The Level of Self-confidence about the protection from risk due to the competitive position (LSPR)

7 - The Level of Observance of the Work Norms on the part of the workers (LOWN)

The Albanian SMEs should aim at maintaining these elements at high levels to minimize as much as possible the cultural risk (which is the dependent variable), because the higher the levels of these elements are the lower the cultural risk is. 


\section{Review of Literature}

The definitions of the cultural risk differ according to the various viewpoints of different scholars, but all of these definitions are based on the concept of the culture of the organization. According to Edgar Schein (2010) the culture of the organization is a pattern of suppositions formed, discovered or otherwise developed by a certain group, while it learns how to cope with the problems of adapting to the external environment and integrating into the inside environment, and which has functioned so well as to be deemed worthy of being transmitted to the new members as a right way to be perceived, and felt in relation to those problems.

According to Cameron and Quinn (2011) the culture of an organization is reflected in its value, in the style of leadership, in the language and symbols, in the procedures and common rules, and in the determination of success which the organization achieves as a single entity.

According to Alvesson (2002) it is emphasised that culture initially is not "inside" the head of the people, but it is somewhere "among" the minds of the people of a group where the symbols and the meanings are expresed publicly.

According to Levy et al (2010) the cultural risk of the organization has to to do with the norms of behaviour of the individuals and groups within the organization which determine the ability to identify and evaluate, to have open discussions and to act in the conditions of actual and perceived future risk.

According to FSB (2014) the cultural risk like the culture of organization develops with the passing of time into the relationships and events which affect the history of the organization. Moreover this risk consists in the fact that the workers of every department of the organization carry out their duties in a legal and ethical manner.

The cultural risk has received a lot of attention especially after the financial crisis which started in 2008 in The USA and spread also in Europe. According to Power et al (2012) it is emphasised that to understand the cause of the crisis first it should be understood the role which the culture of the financial organizations has played and that this culture should be changed, irrespective of how this should be done, it is necessary that the trust in organizations return and that we make sure that similar crises do not happen in the future.

So, different scholars think in the same way when it comes to studying cultural risk together with the culture of the organization. In this context, the study of the risk in this article has been done based on the highlighting of the culture of SMEs in the Gjirokastra region and how the cultural elements of the organization affect the cultural risk.

\section{Data Analysis}

Around 150 subjects were polled to carry out this study succesfully, which fall into the category of small and medium business, of which 47 responded that they were familiar with the concept whereas 103 responded that they did not know the concept of cultural risk, chart 1.

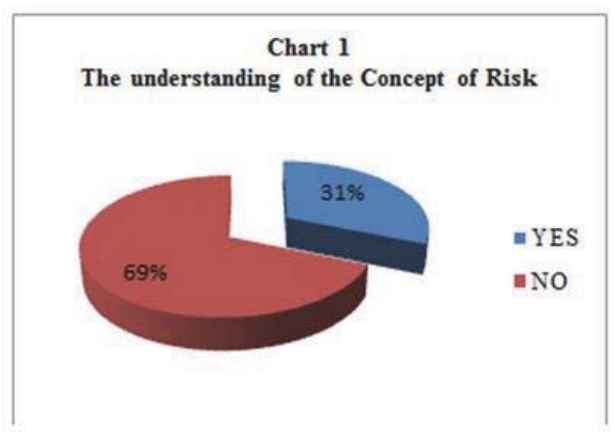

Source: Author, 2014

Of the interviewed subjects 65 of them operate in Commerce (44\%), 20 of them in Production (13\%), 6 of them in Construction (4\%) and 59 of them in Service Sector (39\%), chart 2. 


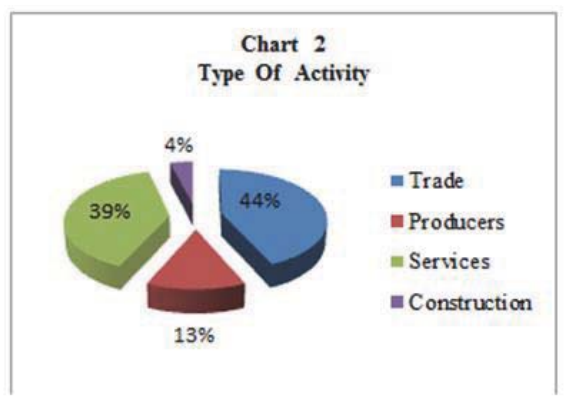

Source: Author, 2014

According to the classification of the number of workers 135 businesses have employed between 1 to 9 workers (90\%), whereas 15 other businesses have employed between 10 to 49 workers (10\%), chart3.

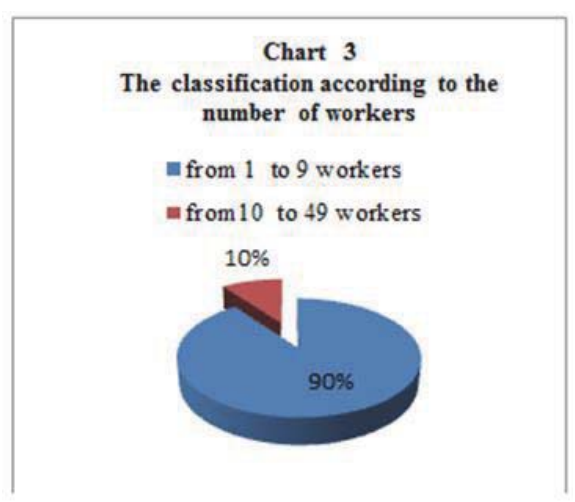

Source: Author, 2014

The data have been processed through SPSS Statistics version 21, by utilizing the logistic regression model. The initial processing of the data has been done through the Enter method, which has been summarily represented according to table 1.

Table 1: Logistic Regression - Block 1: Method = Enter

\begin{tabular}{|c|c|c|c|}
\hline Step & -2 Log likelihood & Cox \& Snell R Square & Nagelkerke R Square \\
\hline 1 & $123.275^{\mathrm{a}}$ & .343 & .481 \\
\hline
\end{tabular}

Source: Output of SPSS version 21, 2014

Table 2 shows the analytical processing of all the data gathered through the questionnaire, by obtaining in this way output 1 of this statistical analysis and equation (1) of the logistic regression. From the processing of the data can be seen that not all the independent variables are important statistics-wise to be included in the model. This can be seen through the level of significance (Sig.) according to which the variable "The level of reaction to mistakes the organization made in the past" (LRMP) and the variable "The level of observance of the work norms on the part of the workers" (LOWN) have very good significance levels (Sig < 0.05) and also quite high positive coefficents, concretely 2.021 and 2.402.

The variable with the highest influence according to the odds ratio level is "The level of observance of the work norms on the part of the workers." (LOWN) variable, which has a very high odds ratio 11.048, which means that the chance to influence the cultural risk increases approximately 11 times for each increase by one unit of LOWN.

The second most influential variable is the (LRMP) variable with a very good odds ratio of 7.547 , which means that 
the recognition, acceptance and reaction to mistakes made in the past affect the level of cultural risk approximately 7.5 times. Whereas the other variables have much lower odds ratio levels than the two abovementioned variables, which means that they affect the cultural risk less than the other two variables "The level of observance of the work norms on the part of the workers" and "The level of reaction to mistakes the organization made in the past".

Also the high level of coefficient of the constant $(-20.928)$ indicates that in the absence of the elements that we study, the cultural risk should be very high and dangerous for the organization. This means that if no value, norm or level of culture exist inside the organization, its activity is destined to fail, due to the very high level of risk.

Table 2: Variables in the Equation (output 1)

\begin{tabular}{|c|c|c|c|c|c|c|c|c|c|}
\hline & \multirow[b]{2}{*}{ B } & \multirow[b]{2}{*}{ S.E. } & \multirow[b]{2}{*}{ Wald } & \multirow[b]{2}{*}{ Df } & \multirow[b]{2}{*}{ Sig. } & \multirow[b]{2}{*}{$\operatorname{Exp}(B)$} & \multicolumn{2}{|c|}{ 95\% C.I.for EXP(B) } \\
\hline & & & & & & & & Lower & Upper \\
\hline \multirow{8}{*}{ Step 1a } & LOC & -.135 & .348 & .150 & 1 & .698 & .874 & .441 & 1.729 \\
\hline & LOT & -.094 & .257 & .134 & 1 & .714 & .910 & .550 & 1.507 \\
\hline & LOPNI & .191 & .353 & .293 & 1 & .589 & 1.211 & .606 & 2.419 \\
\hline & LRMP & 2.021 & .596 & 11.510 & 1 & .001 & 7.547 & 2.348 & 24.258 \\
\hline & LREC & -.175 & .590 & .088 & 1 & .767 & .839 & .264 & 2.669 \\
\hline & LSPR & .386 & .339 & 1.298 & 1 & .254 & 1.472 & .757 & 2.861 \\
\hline & LOWN & 2.402 & .507 & 22.472 & 1 & .000 & 11.048 & 4.092 & 29.828 \\
\hline & Constant & -20.928 & 4.141 & 25.540 & 1 & .000 & .000 & & \\
\hline
\end{tabular}

a. Variable(s) entered during step 1: LOC, LOT, LOPNI, LRMP, LREC, LSPR, LOWN.

Source: Output of SPSS version 21, 2014

The Regression equation (1):I og $\left(\frac{p}{1-p}\right)=-20.9289-0.135 L O C-0.094 L O T+0.191 L O P N I+2.021 L R M P-$ $0.175 L R E C+0.386 L S P R+2.402 L O W N$

Since the two variables LOWN, LRMP and the constant have very good levels of significance (less than 0.05 ) we carry on processing them by using the Forward Stepwise method (Conditional) presented in Table 3. This method enables the automatic selection of the independent variables which are sufficciently important statistics-wise. Apart from this, the Forward Stepwise method (Conditional), by processing the data from the point of view of the influence on the dependent variable, enables us to see the regresses with higher significance for the dependent variable by entering one by one the most important variables. Table 3, is an output of the Forward Stepwise method (Conditional) which represents the new coefficients of the logistic regression and the respective odds ratios for every step, in the meaning of a new relationship between the dependent variable and the independent variables based on the level of significance, which at every step of this method are at the 0.000 level. It can be seen that the avoidance of the statistically unimportant variables greatly improves the level of significance for the variables which are included in the model.

\section{Block 1: Method = Forward Stepwise (Conditional)}

Table 3. Variables in the Equation

\begin{tabular}{|c|c|c|c|c|c|c|c|c|c|}
\hline \multirow{2}{*}{} & & \multirow{2}{*}{ B } & S.E. & Wald & df & Sig. & \multirow{2}{*}{$\operatorname{Exp}(\mathrm{B})$} & \multicolumn{3}{|c|}{$90 \%$ C.Ifor EXP(B) } \\
\cline { 8 - 10 } & & & & & & Lower & Upper \\
\hline \multirow{2}{*}{ Step 1a } & LOWN & 2.410 & .424 & 32.351 & 1 & .000 & 11.139 & 5.548 & 22.365 \\
& Constant & -11.659 & 1.972 & 34.957 & 1 & .000 & .000 & & 12.804 \\
\hline \multirow{2}{*}{ Outp2 } & LRMP & 1.815 & .447 & 16.525 & 1 & .000 & 6.143 & 2.947 & 20.445 \\
Step 2 & LOWN & 2.266 & .457 & 24.572 & 1 & .000 & 9.639 & 4.545 & \\
& Constant & -19.207 & 3.050 & 39.658 & 1 & .000 & .000 & & \\
\hline
\end{tabular}

a. Variable(s) entered during step 1: LOWN. The regression equation (2): $\log \left(\frac{p}{1-p}\right)=-11.659+2.410$ LOWN

b. Variable(s) entered during step 2: LRMP. The regression equation (3): $\log \left(\frac{p}{1-p}\right)=-19.207+1.815 L R M P+$ 2.266LOWN

Source: Output of SPSS version 21, 2014 
The output of this method as a result of the statistical processing enables us to come to certain conclusions:

1. The Level of the Observance of the Work Norms is of a primary importance for the sensitivity to the cultural risk. The chance to influence the cultural risk increases almost 11 times for each increase by one unit of the level of observance of the work norms (Step 1a).

2. The Level of the Observance of the Work Norms combined with the Level of Reaction to Mistakes the organization made in the Past increases its influence on the cultural risk almost 10 times (odds ratio=9.639) (Step 2b).

Furthermore, in order to assess the degree of influence of the independent variables on one-another we study the correlation coefficients (Pearson Correlation Coefficient $=$ PCC) presented in the table 4 of the matrix of correlation. According to this table we can see that:

$>$ The independent variable of communication (LOC) has a positive correlation to all the other variables of the independent case study. But the strongest correlation it has it with the independent variable of the opposition to new ideas (LOPNI), by PCC $0.782^{\star \star}$ and with quite a good level of significance 0.000 . The second strongest correlation is with the independent variable of the tolerance to the workers (LOT) with a correlation coefficient $P C C=0.587^{\star *}$ and with quite a good level of significance 0.000 . Thus, we can say that Albanian SMEs should pay great attention to the level of communication in their environment. The improvement of communication will have positive effect on the improvement of all the other elements and consequently will lower the level of cultural risk.

$>$ The independent variable of tolerance to the workers (LOT) is not correlated with all the other independent variables. This variable has a positive correlation with the independent variable of communication (LOC), with the independent variable of opposition to new ideas (LOPNI), with the independent variable of reaction to external changes (LREC) and with the independent variable of self-confidence about protection from risks (LSPR). The strongest positive correlation it has it with the variable of communication (PCC $=0.504^{\star *}$ ) and with the independent variable of opposition to new ideas $\left(P C C=0.473^{\star *}\right)$. This is understood by the fact that the more tolerant are the directors of the organization the more will rise the level of communication, but also will rise the level of debate regarding new ideas which emerge inside the organization.

$>$ The independent variable of opposition to new ideas (LOPNI) has a positive correlation at a very good significance level 0.000 (meaning less than 0.01) with all the other independent variables, except for the variable of self-confidence where the level of significance is bigger than 0.01 but smaller than 0.05 , and PCC $=$ $0.208^{*}$. The strongest positive correlation it has it with the variable of communication (LOC), which is expressed in PCC $=0.782^{\star *}$ and significance level 0.000 . This means that the increase of debate and opposition to the new ideas implies also an improved level of communication, by fostering debate inside the organization.

$>$ The independent variable of reaction to mistakes the organization made in the past (LRMP) has a strong correlation with the variable of reaction to external changes (LREC) with PCC $=0.688^{\star \star}$ and with the independent variable of the observance of the work norms (LOWN) with PCC $=0.478^{\star \star}$ for the level of significance 0.000 . According to this correlation it is highlighted that when Albanian SMEs take steps to react to mistakes should at the same time react to the external environment, by understanding the tendencies of this change, and also by demanding the observance of the work norms of their workers.

$>$ The independent variable of reaction to changes in the external environment (LREC) has a strong correlation with the variable of the reaction to mistakes the organization made in the past (LRMP) with PCC $=0.688^{\star *}$ and with the independent variable of observance of the work norms (LOWN) with PCC $=0.537^{\star *}$ for the level of significance 0.000. According to this correlation it is higlighted that when Albanian SMEs take steps to react to changes of the external environment should at the same time react to and reflect on the mistakes made in the past and demand observance of the work norms of the their workers.

$>$ The independent variable of self-confidence about protection from risks due to the competitive position (LSPR) is not in any way significantly related to any of the independent variables. It has a slight positive correlation with the independent variable of communication $\left(P C C=0.266^{\star *}\right.$ and to the independent variable of tolerance $\left(P C C=0.217^{\star *}\right)$.

$>$ The independent variable of the observance of work norms (LOWN) has a strong positive correlation with the independent variables (LRPM) with PCC $=0.478^{\star \star}$ and (LREC) with PCC $=0.537^{\star \star}$, for a level of signficance 0.000. This means that when Albanian SMEs increase the demand for the observance of the work norms they increase the possibility to react to and reflect on the mistakes made in the past and to take steps to react and adapt to changes in the external environment. Whereas with the variable of tolerance to workers (LOT) the 
independent variable (LOWN) is not correlated because the level of signficance is bigger than 0.05 , which means that there is not any clear relationship between the demand for the observance of the work norms of the workers will lead to an increase or decrease in the level of tolerance to the workers inside the organization.

Table 4. Correlations

\begin{tabular}{|c|c|c|c|c|c|c|c|c|}
\hline & & LOC & LOT & LOPNI & LRMP & LREC & LSPR & LOWN \\
\hline \multirow{3}{*}{ LOC } & Pearson Correlation & 1 & $.504^{* *}$ & $.782^{* *}$ & $.329^{9+x}$ & $.392^{*+}$ & $.266^{+*}$ & $.224^{* *}$ \\
\hline & Sig. (2-tailed) & & .000 & .000 & .000 & .000 & .001 & .006 \\
\hline & $\mathrm{N}$ & 150 & 150 & 150 & 149 & 150 & 150 & 150 \\
\hline \multirow{3}{*}{ LOT } & Pearson Correlation & $.504^{* *}$ & 1 & $.473^{\text {t* }}$ & .132 & $.316^{* *}$ & $.217^{\text {t* }}$ & .131 \\
\hline & Sig. (2-tailed) & .000 & & .000 & 109 & .000 & .008 & 109 \\
\hline & $\mathrm{N}$ & 150 & 150 & 150 & 149 & 150 & 150 & 150 \\
\hline \multirow{3}{*}{ LOPNI } & Pearson Correlation & $.782^{* *}$ & $.473^{* *}$ & 1 & $.371^{*+}$ & $.474^{* *}$ & $.208^{*}$ & $.285^{* *}$ \\
\hline & Sig. (2-tailed) & .000 & .000 & & .000 & .000 & .011 & .000 \\
\hline & $\mathrm{N}$ & 150 & 150 & 150 & 149 & 150 & 150 & 150 \\
\hline \multirow{3}{*}{ LRMP } & Pearson Correlation & $.329^{* *}$ & .132 & $.371^{* *}$ & 1 & $.668^{\text {t* }}$ & -.084 & $.478^{*+*}$ \\
\hline & Sig. (2-tailed) & .000 & .109 & .000 & & .000 & .309 & .000 \\
\hline & $\mathrm{N}$ & 149 & 149 & 149 & 149 & 149 & 149 & 149 \\
\hline \multirow{3}{*}{ LREC } & Pearson Correlation & $.392^{*+}$ & $.316^{*+}$ & $.474^{*+*}$ & $.668^{*+x}$ & 1 & .065 & $.537^{*+}$ \\
\hline & Sig. (2-tailed) & .000 & .000 & .000 & .000 & & .432 & .000 \\
\hline & $\mathrm{N}$ & 150 & 150 & 150 & 149 & 150 & 150 & 150 \\
\hline \multirow{3}{*}{ LSPR } & Pearson Correlation & $.266^{* *}$ & $.217^{* *}$ & $208^{*}$ & -.084 & .065 & 1 & .072 \\
\hline & Sig. (2-tailed) & .001 & .008 & .011 & .309 & .432 & & .382 \\
\hline & $\mathrm{N}$ & 150 & 150 & 150 & 149 & 150 & 150 & 150 \\
\hline \multirow{3}{*}{ LOWN } & Pearson Correlation & $.224^{* *}$ & .131 & $.285^{* *}$ & $.478^{*+}$ & $.537^{\text {** }}$ & .072 & 1 \\
\hline & Sig. (2-tailed) & .006 & .109 & .000 & .000 & .000 & .382 & \\
\hline & $\mathrm{N}$ & 150 & 150 & 150 & 149 & 150 & 150 & 150 \\
\hline
\end{tabular}

**. Correlation is significant at the 0.01 level (2-tailed).

*. Correlation is significant at the 0.05 level (2-tailed).

Source: Output of SPSS version 21, 2014

\section{Conclusions and Recommendations}

At the end of this study we can say that the cultural risk is a new and relatively little known notion to Albanian SMEs. Also Albanian SMEs are also not really familiar with the notion of "culture of the organization", a notion which is closely related to the cultural risk.

The independent variables of the case study which affect the cultural risk the most are as follows:

$>$ The observance of the work norms on the part of the workers (LOWN). This independent variable affects the cultural risk the most, which is reflected on odds ratio 11.048 (table 2). This means that Albanian SMEs should demand the observance of work norms of their workers, because this would affect the cultural risk 11 times.

$>$ Reaction to mistakes the organization made in the past (LRMP). The way the organization reacts to wrong moves made in the past certainly affects the cultural risk and this can be seen from the statistical analysis according to which this variable has an odds ratio $=7.547$ (Table 2), combined with all the independent variables we studied. Thus, if Albanian SMEs try to understand and react to past mistakes then this action would affect the cultural risk about 7.5 times.

By observing the correlation coefficients (Table 4) we conclude that:

* The independent variable of the observance of work norms (LOWN) has a strong positive correlation with the independent variables LRMP with PCC $=0.478^{\star *}$ and LREC with PCC $=0.537^{* \star}$, for a level of significance 0.000. This means that when Albanian SMEs increase the demand for the observance of the work norms they increase the possibility to react to and reflect on past wrong moves and to take steps to react to and adapt to changes in the external environment. 
* The independent variable of reaction to mistakes the organization made in the past (LRMP) has a strong correlation with the variable of reaction to changes in the external envionment (LREC) with PCC $=0.688^{\star *}$ and with the independent variable of the observance of work norms (LOWN) with PCC $=0.478^{\star \star}$ for a level of significance 0.000. According to this correlation it is highlighted that when Albanian SMEs take steps to react to mistakes should at the same time also react to the external environment, by understanding the tendencies of this change, and also by demanding the observance of the work norms of their workers.

* The independent variable of reaction to changes in the external environment (LREC) has a strong correlation with the variable of reaction to mistakes the organziation made in the past (LRMP) with PCC $=0.688^{\star \star}$ and with the independent variable of the observance of work norms (LOWN) with PCC $=0.537^{\star *}$ for a level of significance 0.000 . According to this correlation it is higlighted tha when Albanian SMEs take steps to react to changes in the external environment should at the same time react to and reflect on mistakes made in the past, demand the observance of the work norms of their workers.

* The independent variable of communication (LOC) has a strong positive correlation with all the other independent variables of the case study. But the strongest correlation it has it the independent variable of opposition to new ideas (LOPNI), with PCC $0.782^{\star \star}$ and with quite a good level of significance 0.000 . Thus, we can say that Albanian SMEs should pay great attention to the level of communication in their environments. The improvement of communication should have positive effect on the improvement of all the other elements and consequently will lower the level of cultural risk.

It is recommended that Albanian SMEs:

1) Strongly demand the observance of the work norms of their workers, which should be part of the culture of organization.

2) React fast to wrong moves they make. This reaction will lead to a decrease in the cultural risk increasing the chances to success in the future.

3) Walk confidently and adapt to changes in the external environment, trying to be always a step ahead of their competitors in the Albanian environment and abroad.

4) Aim at achieving high levels of communication in their environments. This improved level of communication will lead to healthy debates about new ideas, and out of this climate the best idea will eventually be born.

5) Try to understand more the different kinds of risks they have to deal with every day, because every special risk affects considerably their activity, their monetary transactions, their loss or profit.

\section{References}

Alvesson, M. (2002). Understanding Organizational Culture. California: SAGE Publications Inc.

Bierens, J. H. (2008, October 25). The logit model: Estimation, Testing and Interpretation. Retrieved from http://grizzly.la.psu.edu/ hbierens/ML_LOGIT.PDF

Cameron, S. K., \& Quinn, E. R. (2011). Diagnosing and changing organizational culture - based on the competing values framework. theird edition. USA: josey-bass.

Financial Stability Board. (2014, April 7). Retrieved from http://www.financialstabilityboard.org/wp-content/uploads/140407.pdf

INSTAT. (2013). Shqiperia ne shifra 2012. Tirana.

Levy, C., Lamarre, E., \& Twining, J. (2010). Taking control of organizational risk culture. McKinsey\&Company.

Mano, R. (2005). Regresi Logjistik dhe nje impelemntin i tj ne mikrofinance. Tirana.

Manxhari, M. (2010). Sjellja ne Organizate - Kuptimi dhe Menaxhimi i Aspektit Njerezor ne Organizate. Tirana: Onufri, Albania.

Power, M., Ashby, S., \& Palermo, T. (2012). Risk Culture in Financial Organisations. London.

Schein, H. E. (2010). Organizational Culture and Leadership, 3th edition. USA: Jossey-Bass. 